\title{
Risk and Society - The Changing Patterns of Risk
}

\author{
by Sir Hermann Bondi*
}

I shall speak on the subject of risk in my capacity as an amateur sociologist rather than as a physicist. I will try to live up to that amateurism by discussing rather generally about risk, its acceptability, insuring against it, and the acceptibility of that insurance, be it governmental, be it commercial.

First I wish to discuss the worst of all possible risks, which is war affecting one's own country. We are all agreed that the chief purpose of the defence effort of every country is to act as an insurance against this happening. This is quite a useful yardstick because it shows us how much we are prepared to pay for this insurance. Now in this country defence, very roughly speaking, costs every man, woman and child $£ 300$ a year. In the United States the figure is, of course, very much higher. In continental countries the figure is generally not very different from ours, but there the insurance premium does not only involve money paid in the form of taxes, but in addition involves young men's time in compulsory national service.

We see that our society is quite prepared to make a major effort to pay insurance against what is an exceedingly bad calamity. A measure of $£ 300$ a head, or shall we say roughly $£ 1,000$ or $£ 1,500$ a family, gives us a measure against which to look at other insurance premiums we are or are not prepared to pay. Moreover in this case, there is no debate at all that this is a governmental responsibility. Nobody suggests that you should have your private army or that you should opt out of everything by building yourself a deep shelter with enough stores of food for 50 years. It is agreed that defence can only be a communal governmental effort. As regards this insurance premium against war which our societies are prepared to pay, there is a great deal of debate about exactly how that money should be spent. But I don't think anybody disagrees with the fact that this insurance is necessary and that it is bound to be costly. The precise way it should be done is more under debate than its cost.

Let me mention to you next a different kind of risk with which as it happens I have had professional contact. Some 20 years ago there was great concern in this country about the possibility of a tidal surge of the sea coming up the River Thames and flooding London. The question was: was it worth paying anything to insure against this calamity?

\footnotetext{
* President of the International Science Policy Foundation Ltd, London
} 
It wasn't an easy question to answer. The damage would have been very substantial indeed: loss of the underground railways which would be full of mud, loss of telephone cables and communications and the like. With adequate warning of what would happen, there need be no loss of life. If you put a figure to the financial loss of this disaster and multiplied it by the probability of it occurring in any given year, it would not have been all that much. That, of course, is an expectation value calculation with which I'm sure all of you here are only too familiar. But when I grappled with this problem the philosophy of the problem attracted me because it is a unique kind of event. If it happened that the capital (commercial as well as governmental) of this country was out of action for a few years, it is no use consoling the population with the remark that this was a very unlikely event. They wouldn't be very pleased. It is not a calamity where one can spread the risk, because it is a most unusual incident. Its very possibility of occurrence has some connection with the particular geographic formation of the North Sea and the Thames estuary. So one had to come to the conclusion that if protection is affordable, this disaster is something government should not allow to happen. The precise expectation value in something that is unique, but when it happens is paralysing, seemed to be of little or no relevance. This philosophy has led to the building of the Thames Barrier downstream at Woolwich. (If you have time you might like to see it as it is well worth looking at). The question intrigued me because of the difficulty in saying what sum was reasonable to spend to protect against a unique and not very probable occurrence.

Next consider much more likely events. When one thinks of human life I am always reminded of the story of a little community in the United States getting a request from the Registrar General to tell him what their death rate was. They wrote back saying that just as anywhere else it was one death per person. That is a very reasonable attitude but not entirely the attitude of modern society. If we speak of how society's expectations have changed and are changing in our advanced industrialised countries, then one can perceive a drift towards the idea that really the human being is built to last for ever in a perfectly fit and healthy state. If that does not happen it is somebody's fault and liability. It is the growth of this concept that, I believe, presents insurance with one of its greatest challenges.

The idea now is that when things go wrong then somebody is at fault. You can argue a great deal about where this concept comes from. In some respects I am reminded of our great humorist A. P. Herbert, who referred in some such matter to the "selfless labour of lawyers" creating such a good climate for litigation. Be that as it may, the drift of opinion to find fault somewhere is a very serious matter and one that one has to be taken account of particularly in relation to liabilities. Although I am not an insurer I find this attitude very worrying because as a technocrat I see it impinging on innovation and indeed stifling it. Let me give an example of how these things change. In the 1950's we had a young family. Like all parents with a young family, we then worried through every summer in case one of our children caught polio. Then Dr. Salk came with his new vaccine which very rapidly consigned polio in the industrialized countries to the history books. But on the way there was a most unfortunate occasion when a group of children, through an error, were innoculated with the live virus and they all got polio, although none died or were seriously infected. But very soon we were all free of the fear of polio. 
Now that was in (may I use that term) the happy days of nearly 30 years ago. What would happen in today's climate of opinion? There would have been an awful lot more and longer testing. The tragic incident would in all probability have been avoided, but polio would have raged unchecked for another 5 or 10 years of safety checks on the future vaccine. That is where our liability mentality now does damage. It is preventing real improvements, it is preventing real progress. The way insurers can deal with this problem is somewhat nebulous to me. If you can help us, even expensively, to avoid the worst and most stultifying consequences of these rapidly changing attitudes in our society then I think you will be deserving much more than successful underwriting, I think you will have helped to control a real danger to our society. It expresses itself in many different ways. It is interesting to observe this type of thinking in public attitudes to the developing world: if people are poor then it is somebody's fault. It is not understood that poverty is the natural condition of mankind. At last a sizeable growing fraction of mankind has been able to get out of it. Therefore the general attitude is that where there is poverty in the world somebody is at fault. You may point your finger in different directions at their own leaders, at colonialism, at multi-national companies, etc. It is this attitude to liability that has political as well as material consequences. I don't know how your efforts can help us in this but I do say this attitude of blame is very serious politically and technologically for the whole of society.

How can one make risk more acceptable? I don't know how this can be done. The curious thing is that our populations have such odd attitudes to risk: somebody must make absolutely sure that your place of work is utterly safe and that your working hours are reasonably short, so that you can go off hang-gliding! There are certain directions where people are quite prepared to take risks, perhaps without necessarily blaming other people when things do go wrong, but in other directions the risk must be avoided at all costs, a term that is so worrying. As my old friend Freeman Dyson once said in an article, very few people count the cost of saying "no" to developments. Consider one example from weather and climatic research. I am informed that, although experiments in rain making have generally been a failure, it is not all that difficult in present circumstances to divert the path of a hurricane by a few kilometres through taking proper action on the clouds. Suppose you saw a hurricane approaching a major city from the sea. Diverting it to much less densely populated countryside would reduce the damage and the risk to life by very large factors. Yet if the hurricane goes on unchecked and does a lot of damage in the city, then this is still accepted as nobody's fault. But if you deflected the hurricane successfully from the city and it blows down two sheds in the countryside you would assuredly be liable for this. I don't know how you can help here, but I do remember the very honourable history of your industry and of Lloyd's in particular, 200 years ago. When worried about the great losses at sea around the stormy coasts of this island, Lloyd's decided it would save money to put up lighthouses, actually reducing the risk of wrecks. So there is a history of insurers, in their own interest, actually saving life and limb by measures (that maybe were not universally approved in those days, particularly in those parts of this country on the coastline where people made a lot of money from the flotsam and jetsam that came from the wrecks).

How this should be done today I do not know, but if I may gripe a little I have not noticed that your industry has had a lot of effect on the motor car industry in making sure that the repair bill after a small bump is not quite as expensive as the motorcar makers now make sure it is. The benefit of having easily repairable shells for motor cars is still very hard 
to perceive in the difference between the premiums one pays for different cars. That is in marked contrast if I may say so, to putting up of light-houses on the shores of this country.

Again in the perception of risk, it is the difference of risk perception that is so wide, so difficult to rationalise, so hard to handle and it affects your business because people are prepared to pay quite a lot of money against risks they perceive as being awful but are very grudging about paying premiums against risks that they don't regard so seriously. It is a peculiarity of our times that the slaughter on the roads is ignored. The fact that several thousand people in each of our countries lose their lives on the roads every year, makes very little impact on the public consciousness. It is not easy today to justify the spending of money, public or private on improvements of road safety. The public is quite prepared to pay taxes so that faster, less congested roads can be built, but I think they would soon protest if we spent too much money on making the roads safer without making them faster. Somehow a rare disease that kills 20 people a year can be news, yet the epidemic on the roads that kills many thousands each year is not news.

Of course, the least acceptable of all risks is radioactivity. I would like to tell a little story here that is concerned with nuclear power (I worked in our Department of Energy some years ago). As you all know, granite inevitably contains uranium and so produces radiation. Some granites produce rather more than others. If such rock is common in an area where people like to live in stone built houses, the exposure can be quite considerable. The city of Aberdeen is a beautiful city, built of granite. Since people there like to build their houses out of local stone which is a rather uranium rich granite, the exposure to radiation is really rather high, and in some cases around the limits that are internationally set. If one then looks at the health statistics for all the cities in the United Kingdom, regularly Aberdeen comes out best. But that is not because radiation is good for you. It is because there are other factors vastly more important, but much less talked about. This illustrates the point of the unacceptability of certain risks. It so happens that the average level of education in Aberdeen is higher than anywhere else in this country. I am sure Aberdeen has such a good record because nothing is as important for health as a reasonable level of education. But you get far less shouting about the risks of not going to school than about the risks of minute doses of radioactivity.

The insistence on liability has progressed far further in the U.S. than in this country, and has enormously inflated medical costs there, in particular because of the necessary malpractice insurance. Again one can well ask whether this is to the benefit of the population at large or not. But you see the moment you come to this question of how to compare one risk with another (like not going to school as compared to living in a radon emitting house) you are in trouble because people do not look at the different risks in the same fashion and it is increasingly difficult to get a rational discussion.

We are dealing here with a very difficult area. As I always used to say to my friends and colleagues in areas like nuclear energy, the sad situation is that psychological facts are also facts. We have to accept them in some measure. I find that the lack of understanding of risk constitutes a failure of our educational system. Our media, in particular the more responsible educated ones, feed people on statistics, diagrams and graphs, but we have done 
very little to make people sceptical enough to know that these data may have been dressed up in one way or the other, and that many different interpretations can be drawn from the same figures. I am a mathematician by trade but in the interests of citizenship I would gladly give up the teaching of mathematics in schools in favour of teaching sceptical statistics and risk assessment.

I want to tell an educational story to show how difficult statistics are to interpret. In early 1968 this country introduced its drink and drive laws with severe penalties for anyone found driving under the influence of alcohol. Immediately the road casualties late in the evening dropped substantially. In every sense this was greeted as a marvellous success for a new law.

When you look at this statistic a little more critically what happened in fact was that people didn't dare to drive to the pub for a drink. Road traffic late in the evening diminished very significantly. To the best of my knowledge nobody has ever investigated whether the drop in casualties was greater or less than corresponded to the drop in traffic. Unless it was proved that the drop in casualties was disproportionally large, there was no moral justification for the law at all. We could easily deal with road casualties by forbidding people to drive altogether. One has singled out one particular use of cars, but until this delicate statistical examination has been carried out, we do not know whether this singling out was justified.

Another story concerns an examination into the effects on people of working at the first nuclear facility, the Hanford plant in the State of Washington. About 10-12 years ago there was a thorough examination of the cause of death of all the people who had ever worked at that plant. It was found that there was a sizeable excess of cancer deaths compared with the causes of death in the general population. This was taken to show just what a nasty thing nuclear material was. But if you looked at the data more carefully this inference wasn't so obvious: Once the health risks of nuclear work were appreciated these people were all put under regular medical examinations. Now we know that one thing where regular medical examinations help is in spotting high blood pressure and similar circulatory diseases. As a result, far fewer of these people had died from this type of disease than in the general population. But of course if you look only at the people who had died then they must have died from something. If circulatory diseases caused a lower proportion of deaths, then other diseases (including cancer) must have caused a higher proportion. Could the greater proportion of cancer deaths be explained wholly or largely by this factor? Comparisons are required. The other people who have similar health checks are air crew, but the comparison is not very good because that group was initially selected for its fitness. But there was no such selection for the nuclear workers. So indeed the interpretation of these figures remains enormously difficult. This is not a commercial for nuclear power. All I am trying to say is that the useful and sensible interpretation of statistics is very difficult, and may often be impossible. For our populations to be fed, as they are, on ill-digested statistics, may do more harm than good. Insurance has to be managed in a way that is acceptable to an often insufficiently educated public, a public that insists more and more that when something goes wrong, somebody must be at fault and liable. Your industry has the difficult task of being effective in such a situation. 